\title{
THE COVID-19 PANDEMIC AND MENTAL HEALTH IN MALAYSIA: CURRENT TREATMENT AND FUTURE RECOMMENDATIONS
}

\author{
Amoneeta Beckstein ${ }^{1 *}$, Balan Rathakrishnan ${ }^{2}$, Paul B. Hutchings ${ }^{3}$ and Noor Hassline Mohamed ${ }^{2}$ \\ ${ }^{1}$ Psychology Department, Webster University Thailand, Phetchaburi, 76000 Thailand \\ 2 Faculty of Psychology and Education, Universiti Malaysia Sabah, Sabah, 88400 Malaysia \\ ${ }^{3}$ Centre for Psychology and Counselling, University of Wales Trinity Saint David, Wales, SA31 3EP United Kingdom
}

Corresponding author: Amoneeta Beckstein

Email: amoneeta@asu.edu

\begin{abstract}
This paper provides an overview of Malaysian mental health in light of COVID-19. It discusses some of the current treatment options and how the crisis is being managed. A focused literature review was conducted. All relevant articles were included in the review. It offers research, policy, and multicultural practice suggestions for reducing the predicted upcoming mental health pandemic. There needs to be a multiculturally competent, multi-pronged public health strategy to address the psychological damage caused both during and after the pandemic. The government, health and mental health sectors, policy makers, and academic experts need to engage in a meaningful collaboration that leads to policies, resources, and actions to prevent future distress. This paper contributes to the knowledge about the mental health impact and response to the COVID-19 pandemic in a less studied country.
\end{abstract}

Keywords: COVID-19, Malaysia, Mental Health, Pandemic, Treatment

\section{INTRODUCTION}

The outbreak of the 2019 novel coronavirus (referred to by its more common name, COVID19 , in the rest of this paper) has impacted upon people around the world, not only directly through infection and death or acute illness, but also indirectly through the impact upon wider health services. For example, modelling of excess death data suggests that almost 9,000 additional non-COVID-19 deaths have occurred in the first half of 2020 in England, likely to be due to people being unwilling or unable to access needed medical care ${ }^{1}$.

Therefore, whilst World Health Organization (WHO) figures, and the world's immediate attention, may focus upon the number of cases and deaths directly relating to COVID-19, a far wider picture is emerging across the globe of healthcare systems pushed to their limits, and the wider impact that the virus may have on the global population. It is also starting to become clear that, in addition to physical health, the mental health (generally defined as psychological, social, and emotional well-being) consequences must also be considered; COVID-19 has not only brought with it a direct threat to health, it has also dramatically altered the ways that people live, work, study, and function in almost every corner of the globe.

Evidence from the few studies already carried out examining the impact of COVID-19 upon people's mental health suggests that we are seeing direct and indirect effects of COVID-19 in these areas just as for physical health ${ }^{2,3}$. It is likely that people will continue to live with the negative consequences that will potentially impact upon their mental health long after the physical elements of the pandemic are brought under control ${ }^{2}$. Evidence from the SARS epidemic in 2003 suggests that many people continued to have psychological distress long after the physical aspects of the outbreak were brought under control $^{4}$, particularly related to stress, anxiety, and depression, and it is expected that this will also be seen in the current pandemic ${ }^{5}$. In the aftermath of disasters, many people report symptoms of post-traumatic-stress disorder, including direct and indirect victims, particularly first responders ${ }^{6}$.

The $\mathrm{WHO}^{7}$ has predicted an increase in substance use, depression, self-harm and suicide. When surveyed, almost half of Americans reported that their mental health has been affected and nearly $20 \%$ said it is having a "major impact" during the current COVID-19 pandemic ${ }^{8}$. It is not too strong a statement to make in saying that every country in the world is likely to be facing a mental health crisis in the coming months and years; but how well resourced are countries and governments to deal with this mental health crisis? This paper will focus upon one country, Malaysia, but the arguments may be pertinent to many more countries as they consider how to address the mental health issues that will undoubtedly be brought about by COVID-19.

\section{METHODS}

A focused literature review was conducted using Google Scholar, Google, PSYCINFO, and EBSCO. A 
total of 57 relevant sources were included in the review.

\section{RESULTS}

Mental Health and Provision of Care in Malaysia Long before COVID-19, Malaysia faced many mental health issues that have negatively affected society on many levels ${ }^{9,10}$. Mental health support requirements have been increasing in the country for a number of years ${ }^{11}$ and it had been predicted that by 2020 mental health would "be the second biggest health problem affecting Malaysians after heart disease"12 (para. 1) with approximately $30 \%$ of Malaysian adults affected ${ }^{13}$. Malaysian adolescents (13-17 year-olds) do not fare much better with approximately $40 \%$ found to be anxious, $18 \%$ depressed, and $10 \%$ stressed $^{14}$, with the latest National Institute of Health $(\mathrm{NIH})^{15}$ 2019 survey identifying childhood mental health as a "hidden epidemic" in Malaysian society.

Malaysia has had a National Mental Health Policy since 1998 and comprehensive mental health plans since 2002. However, there have been a number of challenges to fulfilling the ideals of this policy, including financial and coordination issues, a limited number of trained professionals, disagreements between stakeholders, and "lack of participation of social organizations to serve the social needs of people with mental illness" 11 (p. 284). The lack of well-trained mental health professionals and even fewer specialists in Malaysia has been commented upon previously by a number of researchers ${ }^{16,17}$. Malaysia has a population of approximately 32.37 million people ${ }^{18}$, yet as recently as 2018 there were only 410 psychiatrists, a ratio of $1.27: 100,000$, which is much lower than the WHO's recommended number of $1: 10,000^{11}$. In Malaysia, there are only approximately 140 clinical psychologists ${ }^{19}$, and the president of PERKAMA International (the organization that represents counselors) estimates approximately 17,000 qualified counselors, a ratio of approximately $1: 1,900$ when the recommended ratio is $1: 500^{20}$. Even then, this estimate of qualified counselors is significantly higher than the number of officially registered counselors in 2018, which was 8,03921. Therefore, the ability of health care professionals to support people throughout such a crisis as COVID-19 may bring is questionable, simply on weight of numbers.

In general, prior to the outbreak, mental health tended to be treated in general or psychiatric hospitals or primary care settings, yet it has been recommended that it be integrated with or transitioned to community based services ${ }^{11}$. The Ministry of Health $(\mathrm{MOH})$ has a Mental Health and Psychosocial Support (MHPSS) action plan to respond to disasters on three levels: district, state, and national ${ }^{22}$; this plan has been in place since 2013 and was recently updated in $2019^{23}$.
The MHPSS team conducts mental health assessments, consultations, and interventions, and as-needed referrals. A team will usually consist of psychiatrists, clinical psychologists, counselors, medical officers, allied health professionals, and a senior hospital administrator $^{24}$. However, as has been commented on above, the number of trained professionals capable of carrying out this type of support is limited. Individual mental health providers on the MHPSS team have had caseloads of around 40 to 80 cases daily, and this might increase over the coming months. The MHPSS providers call clients via audio or via video call for 5-10 minutes to check on their psychological wellbeing and inquire about symptoms, emotions, unhealthy habits or coping, etc. ${ }^{23}$. For those who might need more extensive care, the MHPSS team will make recommendations or referrals to counseling or psychiatric sessions or to specific agencies such as the Welfare Department in order to provide for other identified needs ${ }^{23}$.

Since the governmental changeover in Malaysia in 2018, advocacy of mental health improvements appears to be taking place, with particular support from the deputy prime minister ${ }^{11}$; however, making changes to a health care system takes time and it is highly likely that the current crisis facing the country from COVID19 will arrive before fully trained professionals can be put in place to deal with it. Therefore, it is of paramount importance for a nation such as Malaysia to identify where the mental health crisis is most likely to occur in order to direct the limited available resources to those areas. In this respect, the extant literature from psychological research and previous pandemics can provide guidance.

\section{Social Isolation}

In Malaysia, as of November 2, 2020, the COVID19 infection rate reached 33,339 with 251 deaths, 9,968 active cases, and 23,120 who had recovered $^{25}$. Malaysia was one of the first ASEAN countries to put in place a Motion Control Order (MCO) (quarantine/lockdown) nationwide to reduce COVID-19 infections ${ }^{26}$. The governmentimposed MCO generally restricted people's ability to gather in groups and travel both within Malaysia and internationally, and most nonessential businesses and services were suspended $^{27}$. The initial MCO was from March $18^{\text {th }}$ to $31^{\text {st }}, 2020^{28}$. However, as new cases continued to rise, the MCO was extended to April $28^{\text {th }}$ and then May $12^{\text {th }}, 2020$ with a possibility of being extended further ${ }^{26,29}$. It was then announced that Malaysia would be under a Conditional Movement Control Order (CMCO), a slightly more relaxed version of the original MCO, until June $9 \mathrm{th}^{30}$.

Both the direct and indirect effects of COVID-19 and the subsequent MCO/CMCO will undoubtedly pose challenges to Malaysian's mental health, 
during and after the event. Shanmugam et al. ${ }^{31}$ have argued that the social effects of isolation on mental health can be profound, including increases in anxiety disorders, obsessivecompulsive disorders, and posttraumatic stress disorders. In this respect their argument is similar to that of many preliminary research studies from across the world $3,5,8,32,33$. Most Malaysians, as in other societies, have been selfisolating and social distancing which is likely to adversely affect their psychological wellbeing just as it will those in other societies.

Quarantine and being socially isolated has been associated with psychological distress ${ }^{34}$. These are problematic because humans have naturally evolved to seek connection and affection from others ${ }^{35,36}$. Loneliness and social isolation have been shown to have a negative association with good physical and mental health and even significantly increased mortality rates ${ }^{37,38}$. Since humans are such social creatures and face-toface contact seems to be imperative to our psychological well-being ${ }^{39}$, it makes sense that being deprived of it due to fear of contracting COVID-19 is likely to cause many Malaysians to suffer psychologically.

Furthermore, lack of connection and social isolation may increase addictive behaviors and substance use ${ }^{40}$. People have been advised to avoid or reduce such behaviors ${ }^{41}$ as ways of coping with the pandemic. This advice seems particularly relevant for Malaysians since addictive behaviors and substance use are considered deviant behavior in Malaysian society ${ }^{42}$. However, the $\mathrm{NIH}^{15} 2019$ report also identifies that alcohol and drug use continues to be an issue in Malaysian society, particularly in low-income males, one of the demographic groups likely to be impacted by the economic effects of COVID-1943.

This pandemic adds additional stressors for low income Malaysians or those who lack income with women, children, and youth appearing to be most vulnerable ${ }^{43}$. It has been reported that the unemployment rate is currently at the highest it has ever been for the past ten years and this is directly attributable to COVID-1944,45. Therefore, financial stressors are predicted to cause more mental health concerns for Malaysians postCOVID-19 and, relatedly, there has been a reported increase in domestic violence in Malaysia since COVID-1946. Children and other vulnerable individuals may be at risk of domestic violence and the associated mental and physical health issues that go with it. Between social isolation, substance use, financial stressors, and domestic violence, the mental health of many vulnerable Malaysians' is likely to be adversely affected both during and after this pandemic.

\section{Multicultural Considerations}

Malaysia is a diverse country; the state of Sabah alone has more than 50 ethnicities ${ }^{10}$. Some Malaysian communities tend to have more traditional beliefs and use traditional healers that may not be in alignment with modern mental health treatment modalities that come primarily from Western theories ${ }^{47,48}$. There is still a lot of stigma in Malaysia about mental health, with some believing it is not acceptable have life problems ${ }^{20}$. This includes internalized stigma which might lead people to not be honest about their conditions and not seek help at times of distress ${ }^{46}$.

One of the National Mental Health Policy's main principles is "accessibility and equity" 49 . Promotion programs have been put in place, such as the "Let's TALK Minda Sihat" one, and this can be helpful in reducing stigma ${ }^{46}$. However, multiculturally sensitive mental health services appear to be lacking in Malaysia as a whole ${ }^{11}$.

\section{Current COVID-19 Mental Health Treatment in Malaysia}

Malaysia is as likely as any other country-or possibly even more so-to experience devastating mental health consequences from this pandemic. The Malaysian government and the health care industry, especially the mental health care sector, need to be prepared for an increase in stress, depression, anxiety, substance use, trauma and even suicide among the people.

Most Malaysian hospitals provide some form of mental health care that can ease the toll of the pandemic. For people who have pandemic related distress, Mercy Malaysia (a volunteer organization) and the Ministry of Health $(\mathrm{MOH}$; governmental agency responsible for mental health services) have started a mental health support service and hotline $\mathrm{5}^{50,51}$. Some Malaysians may be more vulnerable than others, including medical frontline staff, the elderly, those in lowincome groups, those with chronic medical conditions, and those with existing mental illnesses ${ }^{50}$. This is true both physiologically and psychologically. For example, in the case of medical frontline staff, the risks of contracting COVID-19 are higher, and the stress of dealing with that fact alongside the trauma of delivering medical care during a pandemic make them susceptible to mental health stress and fatigue $^{5,51}$. For those who have lost their income and need to support themselves and their families, the stressors can be acute ${ }^{52}$.

As in many other countries, a number of mental health providers in Malaysia have started to provide telepsychology via audio or video calling. Some Malaysian universities provide telepsychology and even some in-person counseling for more severe cases for their students. The MHPSS plan has been implemented and provides Psychological First Aid Services and 
Psychological Support to infected people, quarantined people suspected of having COVID19 , other responders involved with the virus, and healthcare workers. Since the beginning of MCO, they have had to complete a Depression, Anxiety and Stress Scale prior to returning to work ${ }^{22}$.

\section{DISCUSSION}

For the last two decades, researchers have highlighted that inadequate services and specialists for Malaysian populations exist ${ }^{11,17}$ and this still appears to be the case as we enter the COVID-19 mental health crisis. Hassandarvish ${ }^{46}$ has argued that the country faces a "silent mental illness pandemic" and that it is the responsibility of the government and other stakeholders to come together urgently to address the crisis and prevent potential serious consequences for those who may be affected. Mental health plans already exist on paper and Midin et al. ${ }^{11}$ have laid out concrete goals and directions that can be followed to serve as guidelines in improving services peri- and postCOVID-19. The trends towards community based treatments 9 that were occurring prior to the outbreak should continue to be supported.

One relevant way of integrating mental health treatment into the community would be to use more mobile units ${ }^{16,53}$ which are likely to be effective during and after COVID-19. For a number of years, Malaysia has had some mobile psychiatry teams that provide services in people's homes. More of these units, equipped with a range of mental health professionals, could be put into operation. Investing more in telepsychology training, technology, promotion, and widespread dissemination has also been recommended with particular focus on vulnerable and disadvantaged groups, especially those who may be victims of the digital divide ${ }^{2}$.

There also needs to be effective communication and collaboration across all relevant sectors and at all levels from the community members all the way up through the government ${ }^{16}$. Never before has it been as crucial to implement "coordinated comprehensive mental health care"11 (p. 282) in the form of mental health promotion, prevention, early recognition of disorders, and effective treatment and aftercare services $^{9,11,16}$. Furthermore, there is a need for expanded training of mental health professionals ${ }^{9,53}$, inter-agency collaboration, and increased services at all levels ${ }^{53}$. There also needs to be more collaboration between government and educational institutions ${ }^{10}$. The government, health and mental health sectors, policy makers, and academic experts need to engage in meaningful collaborations that lead to policies, resources, and actions to prevent future distress. This kind of multi-pronged approach will likely be the most effective at preventing dire mental health outcomes in the current crisis and beyond.

As a way forward, mental health professionals can assist in decreasing people's distress from COVID-19 and help them recover faster mentally, emotionally, and physically. Vulnerable Malaysians such as medical staff, the elderly, those with existing physical and mental concerns, and those at risk of suffering from social isolation, substance abuse, domestic violence, and financial stressors merit special attention. There also need to be policies to support mental health professionals themselves to prevent burnout of which they were particularly susceptible even before the current pandemic ${ }^{54}$. While there is a lack of research about mental health literacy and help seeking among Malaysians, both are likely to be low ${ }^{47}$ which may make the consequences of COVID-19 worse. While both the aforementioned literacy and help seeking behaviors are possibly on the rise $^{11}$, there is still a need for more mental health awareness, de-stigmatizing education, and multiculturally appropriate mental health services ${ }^{16}$. These multicultural issues must be taken into consideration when developing treatment and policies to help Malaysians cope with the adverse effects of the current pandemic.

The general public should "be empowered to play a more active role in maintaining their [mental] health" (p. 165) rather than only relying on mental health professionals 9 . One way of doing that is by training lay people in psychological first aid which is likely to be helpful during pandemics in general and COVID19 in particular ${ }^{50,55}$. Providing psychological first aid training to as many people as possible, especially those who may be interacting frequently with the public, seems particularly pertinent given the rapid response the current crisis requires and the usual timescales required to train mental health professionals.

The previously mentioned hotline, other collaborations, and support measures that have been set up during the pandemic should continue to support the Malaysian population post-COVID19 to help recuperate and build resiliency ${ }^{50}$. It has been suggested that, despite some of the negative effects, there can also be positive impacts from this pandemic on Malaysians' mental health ${ }^{31}$; there are also possibilities of post-traumatic growth ${ }^{56}$. COVID-19 may actually help Malaysians unite as they cope with the collective threat ${ }^{57}$. We further that this can be an optimal opportunity to improve the mental health delivery and infrastructure of the country.

We echo and further Shanmugam et al.'s ${ }^{31}$ call for more empirical studies that explore how all stakeholders can better help those Malaysians psychologically affected by COVID-19. To date, 
there have been no studies in Malaysia that have explored how COVID-19 and the MCO might affect Malaysians' psychological well-being. In line with Qiu et al. ${ }^{3}$, we encourage investigation into the psychological distress caused by COVID19 and we further propose that Malaysia needs to have a comprehensive plan for treating those effected through empirically based treatments.

\section{CONCLUSION}

In conclusion, we propose that researchers begin examining these issues in order to develop an empirically based response that will mitigate the mental health effects on the Malaysian population. Such studies have potential to not only help Malaysians but might have implications for other Asian countries or Asians living abroad. Furthermore, academics, the government, policy makers, and the health/mental health sectors should collaborate to come up with fast, effective, empirically-based solutions to lessen the potential harm.

\section{Conflict of interest}

The authors declare no potential conflict of interest.

\section{REFERENCES}

1. Forchini $G$, Lochen $A$, Hallett $T$, et al. Excess non-COVID-19 deaths in England and Wales between 29th February and 5th June 2020. MRC Centre for Global Infectious Disease Analysis, Imperial College London; 2020. Report 28. [cited Aug 15, 2020]. Available from: https: / /www.imperial.ac.uk/mrc-globalinfectious-disease-analysis/covid19/report-28-excess-deaths/.

2. Figueroa CA, Aguilera A. The need for a mental health technology revolution in the COVID-19 pandemic. Front Psychiatry 2020; 11(523):1-5. doi: 10.3389/fpsyt.2020.00523, PMID 32581891.

3. Qiu J, Shen B, Zhao M, Wang Z, Xie B, Xu $Y$. A nationwide survey of psychological distress among Chinese people in the COVID-19 epidemic: implications and policy recommendations. Gen Psychiatry 2020; 33(2):1-3. e100213. doi: 10.1136/gpsych-2020-100213, PMID 32215365.

4. Gardner PJ, Moallef P. Psychological impact on SARS survivors: critical review of the English language literature. Can Psychol 2015; 56(1):123-35. doi: $10.1037 / \mathrm{a} 0037973$.

5. Torales J, O'Higgins M, Castaldelli-Maia JM, et al. The outbreak of COVID-19 coronavirus and its impact on global mental health. Int $J$ Soc Psychiatry. 2020;66(4):317-20. doi: 10.1177/0020764020915212, PMID 32233719.

6. Neria Y, Nandi A, Galea S. Post-traumatic stress disorder following disasters: A systematic review. Psychol Med 2008; 38(4):467-80.

doi: 10.1017/S0033291707001353, PMID 17803838.

7. World Health Organization. Mental health and COVID-19. World Health Organization 2020 [cited May 27, 2020]. Available from: http: / /www.euro.who.int/en/healthtopics/health-emergencies/coronaviruscovid-19/novel-coronavirus-2019-ncovtechnical-guidance-OLD/coronavirusdisease-covid-19-outbreak-technicalguidance-europe-OLD/mental-healthand-covid-19.

8. Achenbach J. Coronavirus is harming the mental health of tens of millions of people in U.S., new poll finds. The Washington Post 2020 [cited May 15, 2020]. Available from https: / /www.washingtonpost.com/healt $\mathrm{h} /$ coronavirus-is-harming-the-mentalhealth-of-tens-of-millions-of-people-inus-new-poll-finds/2020/04/02/565e674474ee-11ea-85cb-

8670579b863d_story.html.

9. Jamaiyah H. Community mental health in Malaysia: marriage of psychiatry and public health. Bul Kesihatan Masyarakat Isu Khas 2000:155-66. [cited May 27, 2020]. Available from https: / / core.ac.uk/download/pdf/11493 316.pdf.

10. Yacob Y. Speech and opening ceremony by Minister of Education and Innovation, Sabah. International Conference on Psychology, Counselling, and Education. Kota Kinabalu, Malaysia: Universiti Malaysia Sabah; 2019, October 31.

11. Midin M, Zainal NE, Lee TC, Ibrahim N. Mental health services in Malaysia. Taiwan J Psychiatry 2018; 32(4):281-93.

12. Bernama. Resolving mental illness issues in Malaysia. The Sun Daily 2018 [Cited May 3, 2020]. Available from: https: / / www.thesundaily.my/archive/re solving-mental-illness-issues-malaysiaYUARCH541062.

13. Institute for Public Health. National health and morbidity survey 2015. IPH; 
NHMS; 2015. [cited May 25, 2020]. Available from: http://iku.moh.gov.my/images/IKU/Doc ument/REPORT/nhmsreport2015vol1.pdf

14. Adolescent Health Survey. NHMS 2017. [cited May 25, 2020]. Available from: http://iku.moh.gov.my/images/IKU/Doc ument/REPORT/NHMS2017/NHMS2017Inf ographic.pdf

15. National Institutes of Health. National health and morbidity survey, 2019: noncommunicable diseases, healthcare demand, and health literacy. Selangor, Malaysia: Ministry of Health Malaysia 2019 [cited Aug 15, 2020]. Available from:

http://iku.gov.my/images/IKU/Documen t/REPORT/NHMS2019/Infographic_Bookle t_NHMS_2019-English.pdf.

16. Low SK, Lee WY. Promoting better health care services for mental health patients in Malaysia. Int J Soc Sci Hum 2015; 5(12):1030-4.

doi: 10.7763/IJSSH.2015.V5.599.

17. Parameshvara Deva M. Malaysia mental health country profile. Int Rev Psychiatry 2004; 16(1-2):167-76. doi: 10.1080/09540260310001635203, PMID 15276949.

18. Department of Statistics Malaysia. Population distribution and basic demographic characteristic report. Kuala Lumpur, Malaysia; 2010 [cited Apr 28, 2020]. Available from: http://www.statistics.gov.my/portal/ind ex.php?option=com_content\&id=121

19. Seal D. The status of clinical psychology in Malaysia. Share Resolve 2018 [cited May 27, 2020]. Available from https://www.psychologist.com.my/thestatus-of-clinical-psychology-inmalaysia/.

20. Hussin A. Special talk by president of PERKAMA international. International Conference on Psychology, Counselling, and Education. Kota Kinabalu, Malaysia: Universiti Malaysia Sabah; 2019, November 1.

21. Kannan HK, Noor MHM. Govt sets target of 11,000 counsellors by 2020: DPM. New Straits Times Online 2018 [cited May 27, 2020]. Available from: https: / /www.nst.com.my/news/nation/ 2018/10/416730/govt-sets-target-11000counsellors-2020-dpm.
22. Ibrahim Nb, Mohd Hashim NA, Ramasamy $S$ et al. Mental health and psychosocial support in COVID-19: Guidelines COVID19. Ministry of Health 2020 [cited May 24, 2020]. Available from https: / / www.moh.gov.my/moh/resource s/Penerbitan/Garis\%20Panduan/COVID19 /Annex_33_Mental_health_and_Psychoso cial_support_23032020.pdf.

23. Ministry of Health. National guidelines and standard operating proceduremental health and psychological support in Disaster. Malaysia Ministry of Health, Mental Health Unit 2019 [cited May 27, 2020]. Available from: https: / /www.scribd.com/document/427 659783/Guidelines-and-SOP-MHPSS-inDisaster.

24. Mental Health Innovation Network. Staff support during COVID-19: MHPSS initiatives from Miri General Hospital, Malaysia; 2020 [cited May 18, 2020]. Available from: https://www.mhinnovation.net/blog/20 20/may/6/staff-support-during-covid-19mhpss-initiatives-miri-general-hospitalmalaysia.

25. The Worldometer; 2020 [cited Nov 2, 2020]. Available from: https: / / www.worldometers.info/coronav irus/country/malaysia/.

26. Khor V, Arunasalam A, Azli $S$ et al. Experience from Malaysia during the COVID-19 Movement Control Order. Urology 2020; 141:179-80. doi: 10.1016/j.urology.2020.04.070, PMID 32339556 .

27. Prime Minister's Office of Malaysia. Restriction of movement order; 2020 [cited May 3, 2020]. Available from: https://www.pmo.gov.my/2020/03/mov ement-control-order/.

28. New Straits Times. Covid-19: movement Control Order imposed with only essential sectors operating. 2020 [cited May 1, 2020]. Available from: https: / /www.nst.com.my/news/nation/ 2020/03/575177/covid-19-movementcontrol-order-imposed-only-essentialsectors-operating.

29. Idris AN. Govt extends MCO for third time to May 12. The Edge Markets 2020 [cited on May 1, 2020]. Available from https: / / www.theedgemarkets.com/articl e/govt-extends-mco-third-time-may- 12 .

30. Yi TX. Malaysia's movement control order to be extended further until Jun 9, says PM Muhyiddin. CNA 2020 [cited May 
28, 2020]. Available from: https://www.channelnewsasia.com/new s/asia/malaysia-covid-19-muhyiddinmovement-control-order-jun-9-extend12718738.

31. Shanmugam $\mathrm{H}$, Juhari JA, Nair $\mathrm{P}$, Ken CS et al. Impacts of COVID-19 pandemic on mental health in Malaysia: A single thread of hope. Malays J Psychiatry Ejournal 2020; 29(1) Available from: https://www.mjpsychiatry.org/index.ph $\mathrm{p} / \mathrm{mjp} /$ article/view/536.

32. Li S, Wang Y, Xue J, Zhao N, Zhu T. The impact of COVID-19 epidemic declaration on psychological consequences: A study on active Weibo users. IJERPH 2020; 17(6):2032.

doi: $10.3390 /$ ijerph17062032.

33. Liu X, Liu J, Zhong X. Psychological state of college students during COVID-19 epidemic. Lancet Glob Health 2020; doi: $10.2139 /$ ssrn. 3552814 .

34. Brooks SK, Webster RK, Smith LE et al. The psychological impact of quarantine and how to reduce it: rapid review of the evidence. Lancet 2020; 395(10227):91220. doi: 10.1016/S0140-6736(20)30460-8. PMID 32112714

35. Young SN. The neurobiology of human social behaviour: an important but neglected topic. J Psychiatry Neurosci 2008; 33(5):391-2. PMID 18787656.

36. Ebstein RP, Israel S, Chew SH,et al. Genetics of human social behavior. Neuron 2010; 65(6):831-44. doi: 10.1016/j.neuron.2010.02.020, PMID 20346758.

37. Hawkley LC, Cacioppo JT. Loneliness matters: A theoretical and empirical review of consequences and mechanisms. Ann Behav Med 2010; 40(2):218-27. doi: 10.1007/s12160-010-9210-8.

38. Holt-Lunstad J, Smith TB, Baker M, Harris $T$, Stephenson D. Loneliness and social isolation as risk factors for mortality: A meta-analytic review. Perspect Psychol Sci 2015; 10(2):227-37. doi: 10.1177/1745691614568352, PMID 25910392.

39. Pinker S. The village effect: how face-toface contact can make us healthier and happier. Toronto, Canada: Vintage Canada 2015.

40. Weiss R. Why do people with addictions seek to escape rather than connect? A look at the approach to addiction treatment. Consultant 2016; 56(9):78690.

41. World Health Organization. Coronavirus disease (COVID-19) advice for the public 2020 [cited Apr 20, 2020]. Available from:

https://www.who.int/emergencies/disea ses/novel-coronavirus-2019/advice-forpublic.

42. Rathakrishnan B. Devian Sosial (3rd Ed.). Kota Kinabalu, Malaysia: Penerbit Universiti Malaysia Sabah 2013.

43. International Labour Organization. The socioeconomic impacts of COVID-19 in Malaysia: policy review and guidance for protecting the most vulnerable and supporting enterprises. International Labour Organization 2020 [cited Sep 20, 2020]. Available from: http://ilo.org/wcmsp5/groups/public/ -.asia/---ro-

bangkok/documents/publication/wcms_7 51600.pdf.

44. Kanyakumari D. Unemployment rate in Malaysia at highest in a decade due to COVID-19. Vietnam Insider 2020 [cited May 11, 2020]. Available from: https://vietnaminsider.vn/unemploymen t-rate-in-malaysia-at-highest-in-adecade-due-to-covid-19/.

45. Lim J. Malaysia unemployment rate expected to hit $4 \%$ this year due to Covid-19. The Edge Markets 2020. [cited May 11, 2020]. Available from: https: / / www.theedgemarkets.com/articl e/malaysia-unemployment-rateexpected-hit-4-year-due-covid19.

46. Hassandarvish M. Malaysian expert: silent mental illness "pandemic" to arrive following Covid-19 economic fallout. Malay Mail Life 2020. [cited May 11, 2020]. Available from: https: / /www.malaymail.com/news/life/ 2020/04/28/malaysian-expert-silentmental-illness-pandemic-to-arrivefollowing-covid-1/1860920

47. Chong ST, Mohamad MS, Er AC. The mental health development in Malaysia: history, current issues and future development. Asian Soc Sci 2013; 9(6):18. doi: 10.5539/ass.v9n6p1.

48. Henrich J, Heine SJ, Norenzayan A. The weirdest people in the world? SSRN Electron J $2010 . \quad$ doi: $10.2139 /$ ssrn. 1601785 . 
49. Ministry of Health. National mental health policy. Kuala Lumpur, Malaysia: Ministry of Health Malaysia; 1998.

50. Between the Lines. Battling the beast within: the psychological trauma of Covid-19. Malaysiakini 2020. [cited May 11, 2020]. Available from: https: / /www.malaysiakini.com/news/52 2732.

51. Nortajuddin A. How the pandemic is disrupting mental health. The ASEAN Post 2020. [cited Apr 20, 2020]. Available from:

https: / / theaseanpost.com/article/howpandemic-disrupting-mental-health.

52. Holmes TH, Rahe RH. The social readjustment rating scale. $J$ Psychometric Res 1967; 11(2):213-8. doi: 10.1016/0022-3999(67)90010-4.

53. Kadir A. Community psychiatric services in Malaysia: where do we go from here? Malays J Psychiatry 2011; 20(1).

54. McCormack HM, Maclntyre TE, O'Shea D, et al. The prevalence and cause(s) of burnout among applied psychologists: A systematic review. Front Psychol 2018; 9:1-19. doi: 10.3389/fpsyg.2018.01897.

55. World Health Organization. Psychological first aid for all: supporting people in the aftermath of crisis events. World Health Organization 2016 [cited May 27, 2020]. Available from: https://www.who.int/mental_health/wo rld-mental-health-day/ppt.pdf?ua=1.

56. Tyson B. How can we find personal growth from coronavirus? 2020 [cited Apr 20]. Available from: https: / /www.psychreg.org/personalgrowth-coronavirus/.

57. Nortajuddin A. How Malaysia is winning the war against COVID-19. The ASEAN Post 2020 [cited Apr 20, 2020]. Available from:

https: / / theaseanpost.com/article/howmalaysia-winning-war-against-covid-19. 